\title{
Ares-I-X Stability and Control Flight Test: Analysis and Plans
}

\author{
Jay M. Brandon ${ }^{1}$ Stephen D. Derry ${ }^{2}$ Eugene H. Heim ${ }^{3}$ Richard M. Hueschen ${ }^{4}$ and Barton J. Bacon ${ }^{2}$ \\ NASA Langley Research Center, Hampton, VA 23681
}

The flight test of the Ares I-X vehicle provides a unique opportunity to reduce risk of the design of the Ares I vehicle and test out design, math modeling, and analysis methods. One of the key features of the Ares I design is the significant static aerodynamic instability coupled with the relatively flexible vehicle - potentially resulting in a challenging controls problem to provide adequate flight path performance while also providing adequate structural mode damping and preventing adverse control coupling to the flexible structural modes. Another challenge is to obtain enough data from the single flight to be able to conduct analysis showing the effectiveness of the controls solutions and have data to inform design decisions for Ares I. This paper will outline the modeling approaches and control system design to conduct this flight test, and also the system identification techniques developed to extract key information such as control system performance (gain/phase margins, for example), structural dynamics responses, and aerodynamic model estimations.

\section{Nomenclature}

$\begin{array}{ll}\alpha & =\text { angle of attack } \\ \alpha_{\mathrm{T}} & =\text { total angle of attack } \\ \beta & =\text { angle of sideslip } \\ \mathrm{BDM} & =\text { booster deceleration motor } \\ \mathrm{BTM} & =\text { booster tumble motor } \\ \mathrm{CFD} & =\text { computational fluid dynamics } \\ \mathrm{C}_{\mathrm{m}} & =\text { pitching moment coefficient } \\ \mathrm{C}_{\mathrm{m} \alpha} & =\text { pitching moment stability derivative } \\ \mathrm{C}_{\mathrm{n}} & =\text { yawing moment coefficient } \\ \mathrm{C}_{\mathrm{n} \beta} & =\text { yawing moment stability derivative } \\ \mathrm{DFI} & =\text { developmental flight test instrumentation } \\ \phi & =\text { roll attitude angle } \\ \phi_{i} & =\text { mass normalized eigenvector matrix element } \\ \mathrm{FCS} & =\text { flight control system } \\ \mathrm{FEM} & =\text { finite element model } \\ \mathrm{FTINU} & =\text { fault tolerant inertial navigation unit } \\ \mathrm{GN \& C} & =\text { guidance, navigation and control } \\ h & =\text { height } \\ \mathrm{INU} & =\text { inertial navigation unit } \\ M & =\text { mass matrix element } \\ \mathrm{MLP} & =\text { mobile launch platform } \\ \mathrm{OFI} & =\text { operational flight instrumentation } \\ \mathrm{p} & =\text { body-axis roll rate } \\ \mathrm{PSD} & =\text { power spectral density }\end{array}$

${ }^{1}$ Aerospace Engineer, Flight Dynamics Branch, Associate Fellow.

${ }^{2}$ Aerospace Engineer, Dynamic Systems and Control Branch.

${ }^{3}$ Aerospace Engineer, Flight Dynamics Branch.

${ }^{4}$ Aerospace Engineer, Dynamic Systems and Control Branch, Associate Fellow. 


$\begin{array}{ll}\text { PTI } & =\text { programmed test inputs } \\ \mathrm{q} & =\text { body-axis pitch rate } \\ \mathrm{Q} & =\text { dynamic pressure } \\ \mathrm{r} & =\text { body-axis yaw rate } \\ \mathrm{RoCS} & =\text { roll control system } \\ \mathrm{RRGU} & =\text { redundant rate gyro unit } \\ \mathrm{RSRM} & =\text { reusable solid rocket motor } \\ \theta & =\text { pitch attitude angle } \\ \mathrm{TAT} & =\text { total air temperature } \\ \mathrm{TVC} & =\text { thrust vector control } \\ \mathrm{T} / \mathrm{W} & =\text { thrust-to-weight ratio } \\ \psi & =\text { yaw attitude angle }\end{array}$

\section{Introduction}

$\mathrm{T}_{\mathrm{h}}$ he vision for space exploration, called the Constellation Program, was authorized by Congress with the NASA

Authorization Act of 2005. This was the basis of the marching orders for NASA to develop not only a replacement vehicle for the Space Shuttle, but also to develop the infrastructure to support manned exploration back to the moon and beyond. The first step of this new space transportation architecture is the Ares I - which is a launch vehicle based on the Space Shuttle Reusable Solid Rocket Motor. The crew will be transported in the Orion Crew Exploration Vehicle mounted on the top of the Ares I. The Ares I is a very tall (over 320 feet) slender configuration. The concept has 2 stages. The first stage is a solid rocket booster, and the second stage is a hydrogen/oxygen rocket system using an engine (J2X) based on the $\mathrm{J} 2$ engine used in the Apollo Program on the second and third stages of the Saturn V. Although the Ares I is developed largely from heritage flight hardware, the overall system is significantly different than the Shuttle or Saturn V, and as such presents challenges in development of accurate mathematical models and ensuring well controlled flight. As a part of the process of developing this vehicle to be a safe and reliable transportation system, a series of tests have been planned. The first flight test of the full stack vehicle will be the Ares I-X, scheduled to fly in 2009. This paper will discuss the aspects of the flight test with application to guidance and control demonstration and model validations, as well as a discussion of the flight test and analysis plans.

\section{Ares I-X Flight Test Objectives}

There are five primary flight test objectives. They encompass flight ascent control, First Stage separation, ground processing, First Stage deceleration and recovery, and roll torque characterization (Table 1). The mission profile and trajectory will be tailored to optimize accomplishment of the primary objectives.

Table 1 Primary Flight Test Objectives

\begin{tabular}{|l|c|}
\hline$\#$ & Objective Description \\
\hline P1 & $\begin{array}{c}\text { Demonstrate control of a vehicle dynamically similar to the Ares I/Orion vehicle using } \\
\text { Ares I relevant flight control algorithms. }\end{array}$ \\
\hline P2 & $\begin{array}{c}\text { Perform a nominal in-flight separation/staging event between an Ares I-similar First Stage } \\
\text { and a representative Upper Stage. }\end{array}$ \\
\hline P3 & Demonstrate assembly and recovery of a new Ares I-like First Stage element at KSC. \\
\hline P4 & $\begin{array}{c}\text { Demonstrate First Stage separation sequencing, and quantify First Stage atmospheric entry } \\
\text { dynamics, and parachute performance. }\end{array}$ \\
\hline P5 & Characterize magnitude of integrated vehicle roll torque throughout First stage flight. \\
\hline
\end{tabular}

As can be seen by inspection of the primary flight test objectives, successful GN\&C system performance must be achieved to meet four of the five primary objectives. 


\section{Ares I Configuration}

The Ares I is a tall slender rocket similar in length to the Saturn V - much taller than the Space Shuttle (Figure 1). The Ares I-X flight test vehicle is designed to simulate the mass properties, performance, and outer-mold-line characteristics of the Ares I. The Ares I uses a 5-segment derivative RSRM booster instead of the 4-segment booster used for Shuttle. Because of the time required to develop the derivative motor, the Ares I-X will

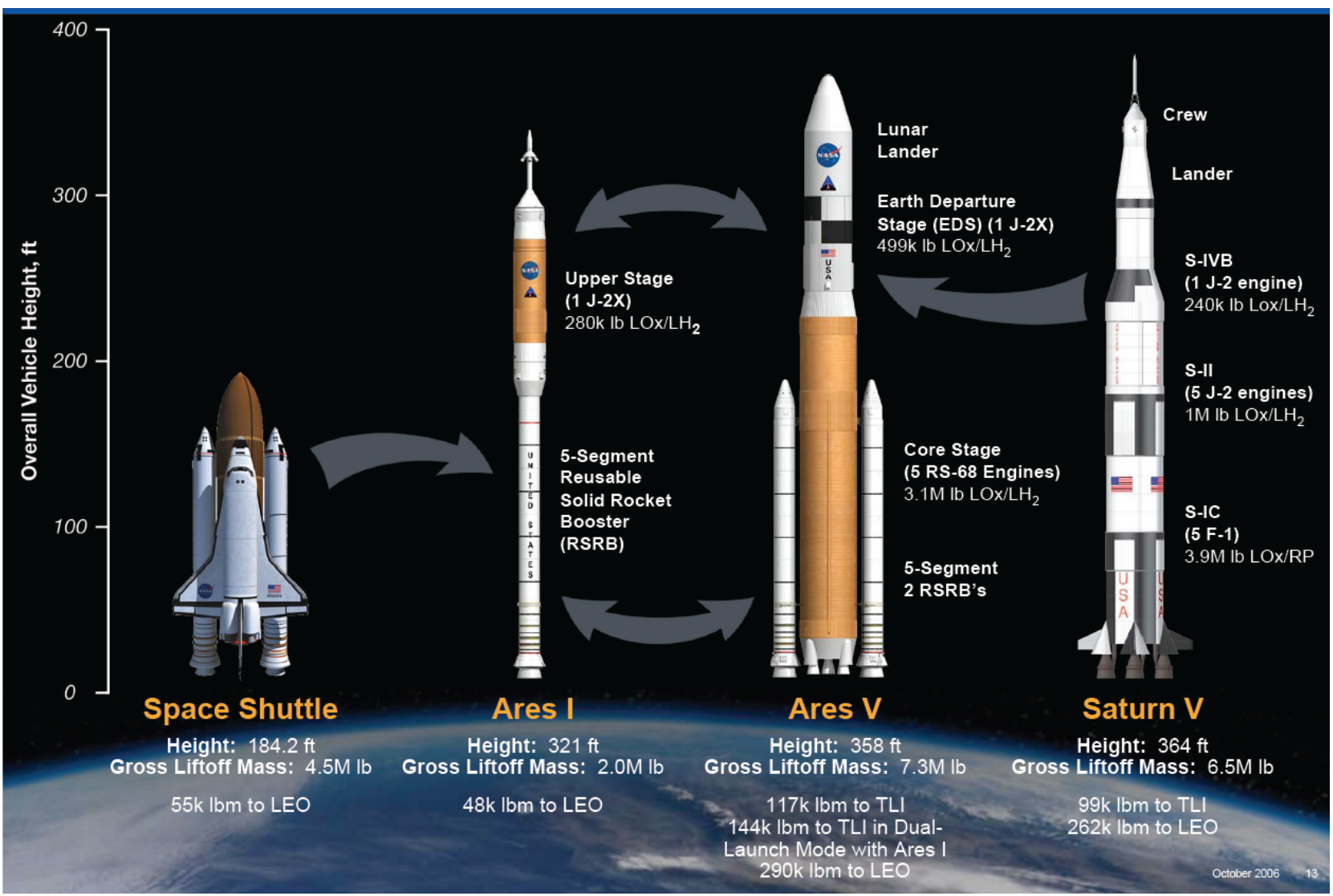

Figure 1 Launch Vehicle Comparisons.

not have a 5-segment motor available and is using a 4-segment Shuttle RSRM. Additionally, a simulator of the $5^{\text {th }}$ segment is included in the Ares I-X to appropriately scale the flight test vehicle to the Ares I. Figure 2 shows the components used for the Ares I-X flight test vehicle. Two more observations of differences between the Ares I and the Ares I-X are that the launch abort system and the interface to the capsule has changed geometry somewhat since the design was frozen for the flight test vehicle. Also, since the Ares I-X is focusing on the first-stage boost flight only, the stage separation plane for the Ares I-X is at the base of the frustum, whereas the stage separation plane for the Ares I is further forward, at the interstage. 


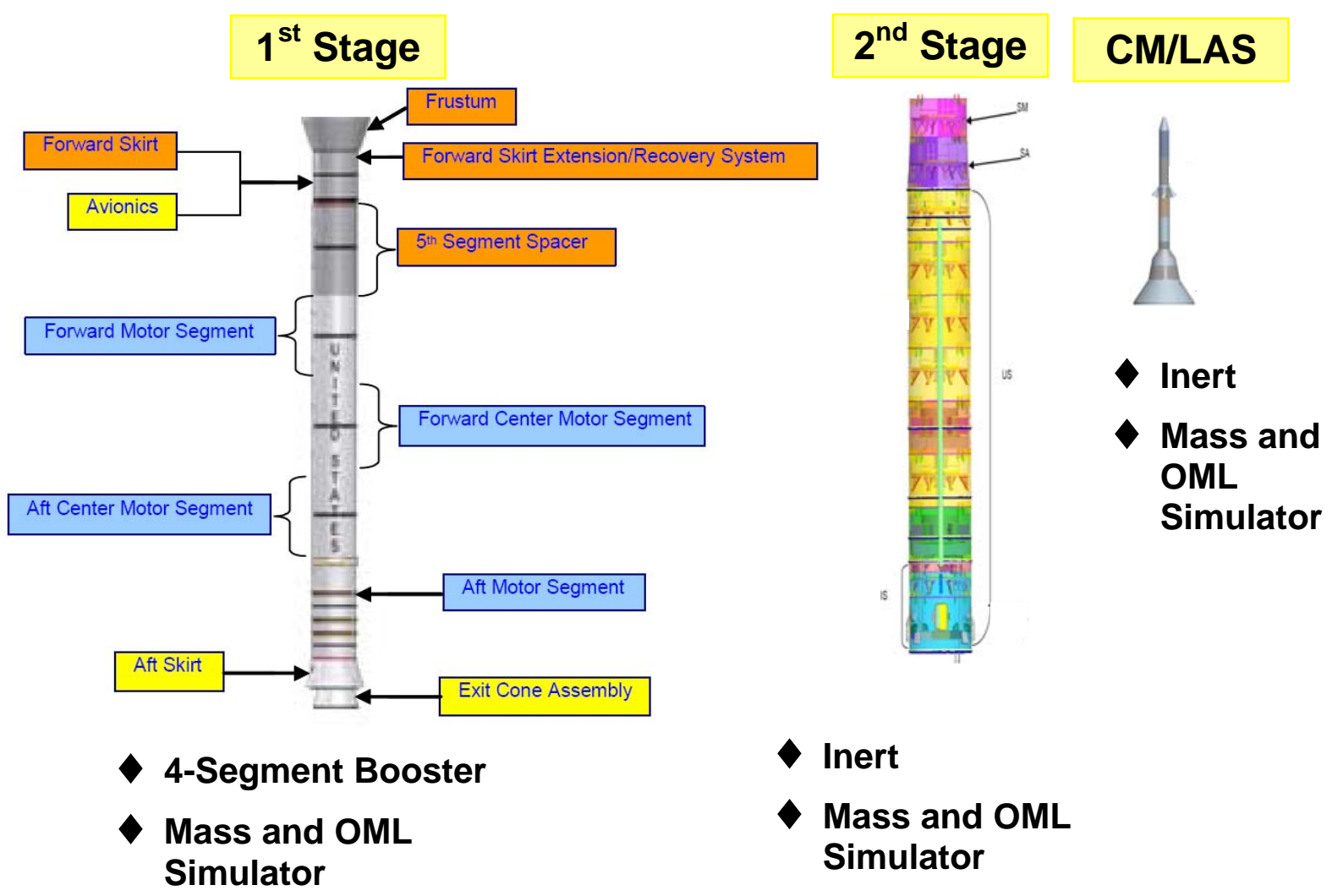

Figure 2 Ares I-X Components

\section{Ares I Stability and Control}

One of the primary focuses of the Ares I-X flight test is to demonstrate control of a vehicle similar to the Ares Iwhich has a slenderness ratio (length to diameter) much higher than other previously flown launch vehicles, as well as aerodynamic instabilities (distance between aerodynamic center of pressure and center of mass) in excess of previous vehicles. Additionally, the overall structure is elastic with first bending modes in the $1-\mathrm{Hz}$ range, so careful flight control system design is required to ensure adequate damping of the elastic structures and avoid adverse flight control-structural interaction. The flight control system architecture design for the Ares I and the Ares I-X is a conventional proportional-integral-derivative controller with filters to provide phase and gain stabilization of the structural dynamics modes. Figure 3 shows the schematic of the flight control system. An example of the importance of the phase/gain stabilization is shown in Figure 4. The flight control system uses a system of sensors along the stack of the vehicle. Due to the flexibility of the vehicle, the phase and amplitude of the feedback signals vary along the stack. Correct placement of sensors, and knowledge of the structural dynamics are required to effectively control the rocket in flight without inducing undesirable motions due to control system-structural dynamics interactions. Without taking the flexibility effects into effect, a standard rigid-body control approach will result in large undesirable motions and loads during flight. With appropriate selection of sensor locations and filter design for phase stabilization of the primary structural dynamics mode, desired flight characteristics can be achieved. The roll axis control system consists of a linear phase-plane control law combined with jet selection logic to ensure that commands to the RoCS hardware do not exceed the system capabilities. The challenge for the roll control system is to be able to control large rolling moments if required, with substantially decreasing roll inertia during flight. The roll torque provided by the thrusters is not adjustable; it is always what is generated by pairs of RoCS thrusters. 


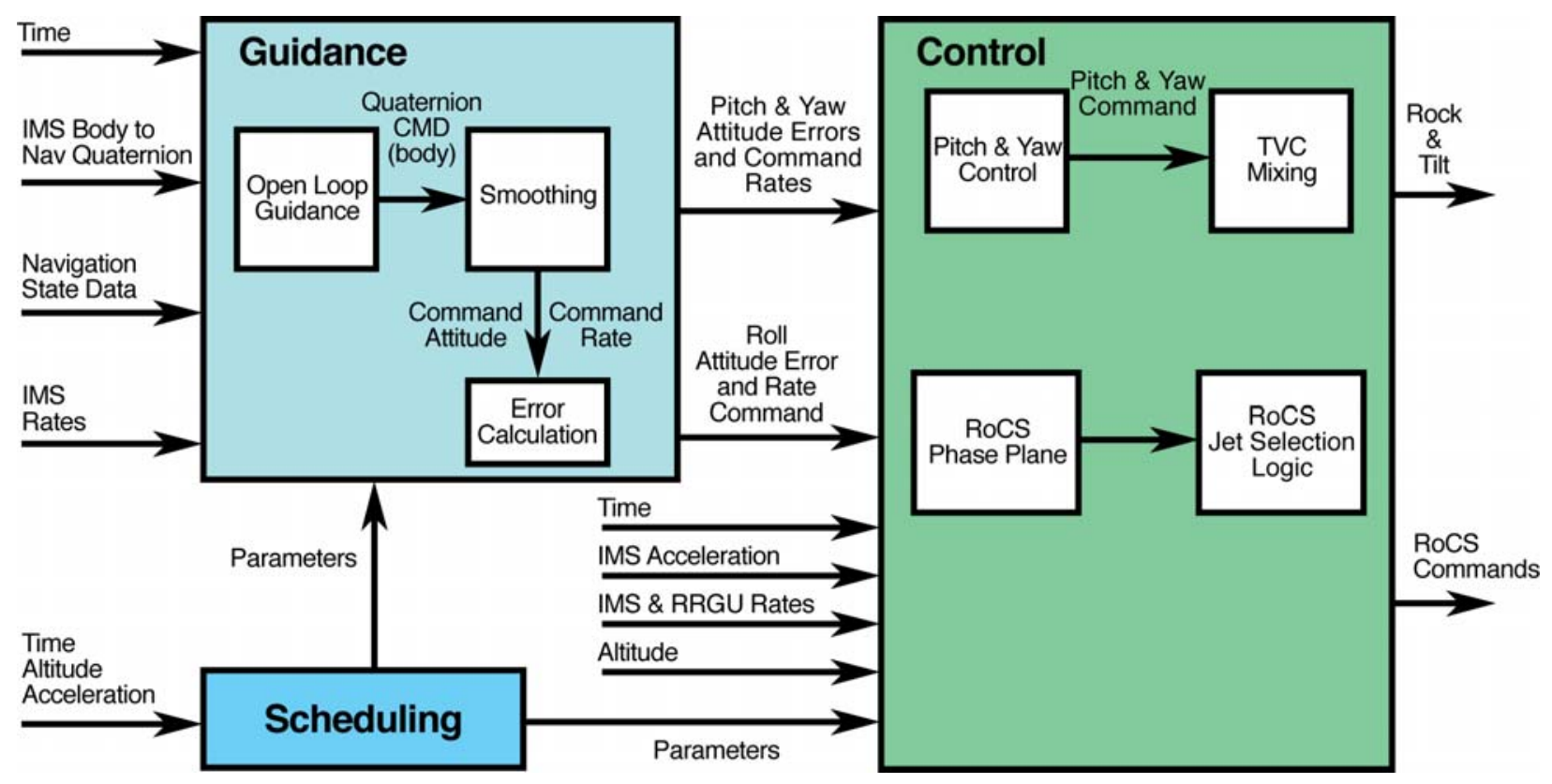

Figure 3 Flight control system architecture.

Structural dynamics model coupled with flight dynamics model

Control approach developed and shown effective in simulation
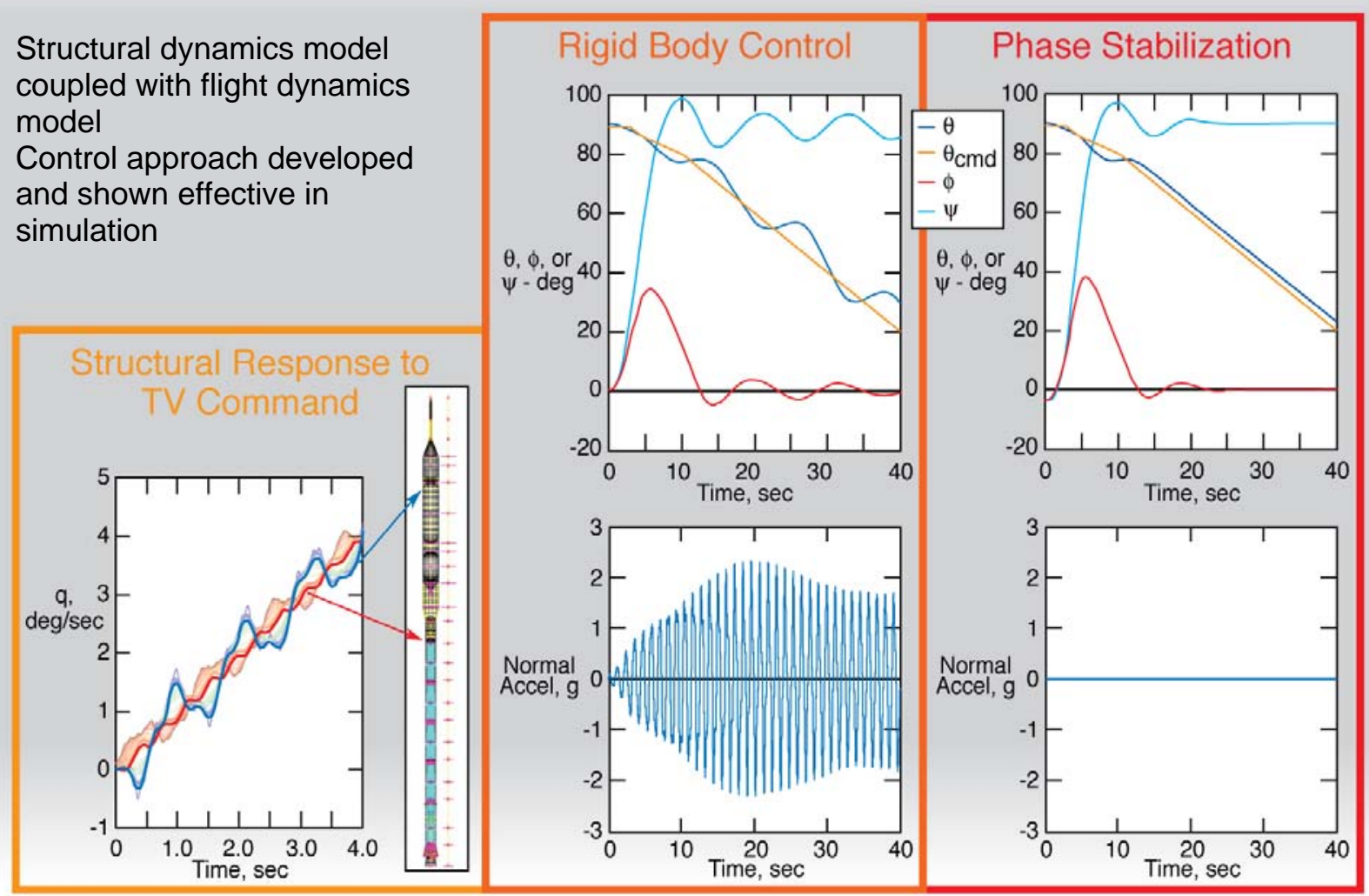

Figure 4 Structures/controls interactions. 


\section{Flight Test Approach}

The Ares I-X configuration is different than the Ares I so development of the flight test needed to be carefully constructed to provide relevant data for design guidance and tool validation for Ares I. One key design aspect was development of similitude parameters to ensure that relevant data would be obtained with the flight test. The Ares I$\mathrm{X}$ has only a 4-segment booster, compared to the Ares I 5-segment design, so overall thrust and performance is reduced for the Ares I-X. Therefore, the overall mass of the test vehicle has been scaled such that the T/W for both configurations is similar. This provides for accurate simulation of the performance aspects of the rocket initially. Additionally, the 5-segment booster burns longer than the 4 segment, so overall performance capability of the Ares I-X will be less. To ensure that flight conditions relevant to the Ares I are obtained, a modified trajectory was designed for the Ares I-X to optimize the combination of Mach, dynamic pressure, angle of attack, and altitude compared to the Ares I. Figure 5 shows candidate trajectory designs. Using the simulation program, POST (ref. 1), optimizations were conducted to provide best matches up to Mach 2, provide for maximum stage separation velocity, and to provide best overall match while keeping the dynamic pressure at or below 100 psf at stage separation. The criterion picked was the limit on the stage separation dynamic pressure, and the trajectory data show very good matching of Mach, dynamic pressure, velocity, and altitude up to about Mach 4.
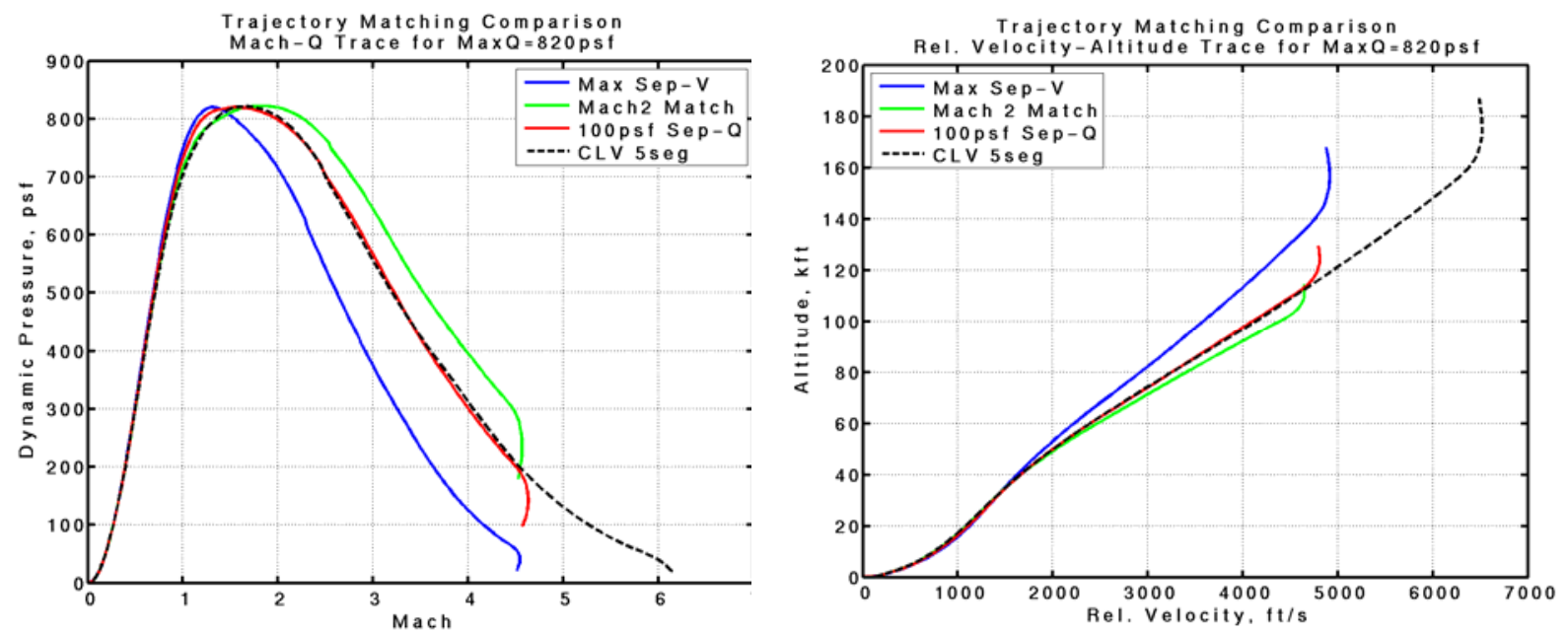

Figure 5 Trajectory design.

Because of the design differences between the vehicles - primarily reduced overall thrust for the Ares I-X flight similarity cannot be maintained for the entire boost envelope of the Ares I. As the trajectory data show, the Ares I-X will conduct its stage separation event around 130,000 feet altitude, dynamic pressure of about $100 \mathrm{psf}$, and 4.5 Mach, rather than the Ares I current design values of around 190,000 feet altitude, dynamic pressure of about 6 psf, and 6.2 Mach.

To accomplish the primary objectives for the flight test with quantitative data, the test vehicle is heavily instrumented with sensors providing information across the disciplines of thermal, structures, GN\&C, and aerodynamics. There are approximately 751 additional sensors (DFI) on board specifically for gathering flight test data in addition to the sensors already available for flying the vehicle (OFI). Figure 6 shows a diagram of some of the primary instrumentation and locations of sensors for the guidance and controls flight test objectives. 


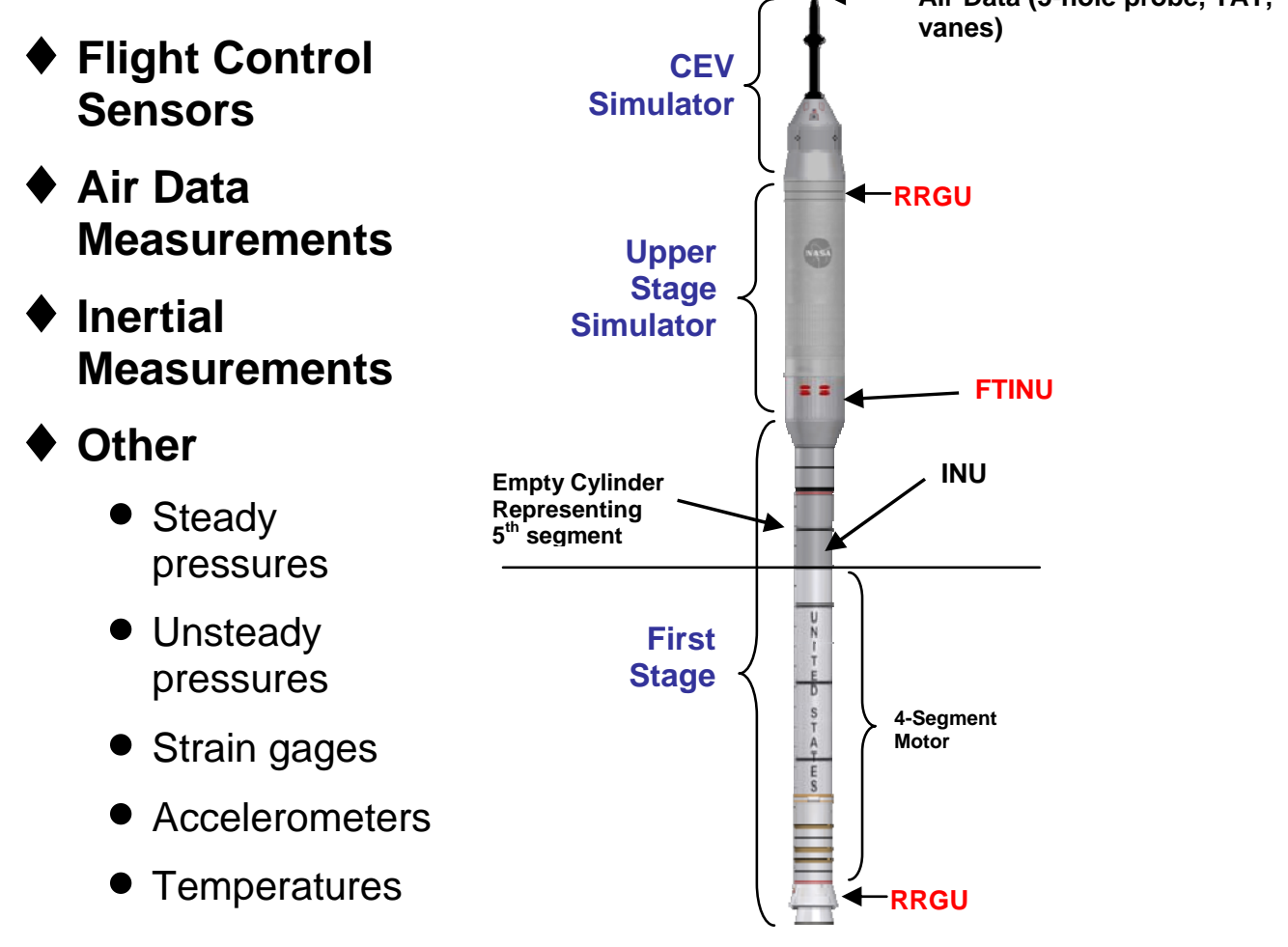

Figure 6 Flight test instrumentation.

\section{Physical Models}

A summary of the types of data used to develop the models and analysis results illustrated in this paper are described below. Due to the fast pace and development nature of the Ares I-X project, these models are frequently updated, and analysis and in some cases design of the flight controls are reevaluated as required.

\section{A. Aerodynamics}

The data include ascent aero, high-angle-of-attack aero (to account for ground winds), base force corrections, distributed aerodynamics, and uncertainties. In addition to the aerodynamic effects, there is a roll torque which is attributed to the combustion of the first stage booster motor and other unknown sources. Data sources for this program, and for Ares I, have been developed using a hybrid approach of CFD and wind tunnel data, with far more emphasis on the computational analysis results than in previous large-scale development programs.

\section{B. Thrust Models}

Thrust models include predicted engine thrust of the RSRM booster, the RoCS thruster outputs, and the BDM/BTM's. Shuttle RSRM's, such as the one being used in this flight, are manufactured in pairs so that for the shuttle, the thrust values will be very close for both boosters to minimize unsymmetrical forces on the shuttle flight. The paired booster for the RSRM being used for the Ares I-X flight has already been test fired, so the performance characteristics of the Ares I-X booster are well known. Corrections to the predicted thrust are made for propellant temperature. The BDM's and BTM's are the same motors that the Shuttle uses for booster separation motors (BSM's), and have shown extremely high reliability in the Shuttle program. The RoCS thrusters are surplus thrusters from PeaceKeeper missiles, and have undergone testing at White Sands to verify and baseline the performance of the RoCS motors for Ares I-X use. 


\section{Structural Dynamics}

Vehicle structural dynamics must be stabilized by the FCS throughout flight. A large percentage of the vehicle mass is composed of propellant which is consumed during the boost phase. This loss of mass significantly changes the structural dynamics as propellant is depleted. A Finite Element Model (FEM) with varying levels of propellant mass (NASTRAN/PATRAN) was used to aid FCS design and analysis for lift-off and first stage flight. Two linear FEM models were used by the Ares I-X GN\&C team; vehicle ascent model and mobile launch platform (MLP) model. The vehicle ascent model was based on a shell model. This model was modified to include 40 centerline nodes along the main body of the vehicle and 2 centerline nodes on the first stage nozzle. All nodes were "wagonwheeled" to the Outer Mold Line (OML) except the first stage gimbal node which was wagon-wheeled to the OML of the nozzle at the gimbal point. The OML nodes were used to model the overall vehicle dynamics. These nodes served as inputs for structural excitation as well as inputs to sensor models. The MLP model was based on a model used by the Space Shuttle program. This MLP model was used with the vehicle ascent model mounted to it to model structural dynamics due to winds at the pad and to capture initial conditions for the free-free ascent modes at lift-off. Vehicle-MLP mounting conditions were limited to the 4 hold down posts connected at this point. Structural dynamics were modeled as linear second order systems with a damping ratio of $0.5 \%$ for each mode. Most structural analyses currently use an estimated damping ratio of $1 \%$, so the $0.5 \%$ value used for flight control analyses is considered conservative. Mode frequencies and shapes were obtained using NASTRAN or PATRAN to solve for the undamped eigenvalues and eigenvectors. Eigenvectors and values for the first stage flight were obtained at discrete vehicle masses of the shell model representing nominal flight times of $\mathrm{T}=0$ to 120 seconds at every 10 second interval. Each time-slice included modes up to $25 \mathrm{~Hz}$ which was expected to include the first 4 bending mode pairs, 1 st axial mode and $1^{\text {st }}$ torsional mode. This cutoff is also well beyond the FCS bandwidth and is the maximum frequency the FCS can resolve. Propellant and other localized modes that did not contribute to overall OML dynamics were removed.

Modal Tracking and Interpolation Dynamics at vehicle mass conditions in between model data points were estimated using piecewise linear interpolation of eigenvectors, eigenvalues, and damping for each mode individually as a function of vehicle mass. The modal interpolation requires prior knowledge of mode identification between the time-slices. NASTRAN/PATRAN has no way of tracking eigenvalues as they change in time. The program simply sorts the modes based on frequency. This presents a problem when interpolating as mode frequencies sometimes cross and thus the sorting order of the modes can change. A technique was developed to assist in "modal tracking". Cross-orthogonality matrices were used to develop a "mode map" for mode shape and sign tracking between the time-slices. The cross-orthogonality matrix is described by eqn 1

$$
\phi_{i}^{T} M_{i} \phi_{i+1}
$$

where $\phi_{i}$ and $M_{i}$ are the full FEM (as opposed to the 42 node GN\&C subset) mass normalized eigenvector and mass matrix respectively at one time and $\phi_{i+1}$ is the eigenvector at the following time. The resulting matrix provides a measure of which mode shapes are similar between the two times. If $\phi_{i}=\phi_{i+1}$ then equation 1 equals the generalized mass which has a value of 1.0. Negative values indicate the mode has swapped sign between the times. Modal coupling still presents a problem when frequencies cross. This typically happens when an axial or torsional frequency crosses a pair of bending mode frequencies (bending pairs are the traditional lateral/longitudinal bending modes orthogonal to one another). In the case where a torsion or axial mode frequency crosses a lateral/longitudinal mode pair, all three modes are coupled and all three modes are required to fully describe any one. Engineering judgment is required when modes combine. Figure 7 illustrates the cross-orthogonality matrix between time-slices at $\mathrm{T}=20$ and $\mathrm{T}=30$ seconds. Modes 1 through 12 have remained in the same order while the frequencies of modes 13, 14, and 15 have become essentially coalescent. Manual inspection of the eigenvectors was used to sort modes that have coalesced. 


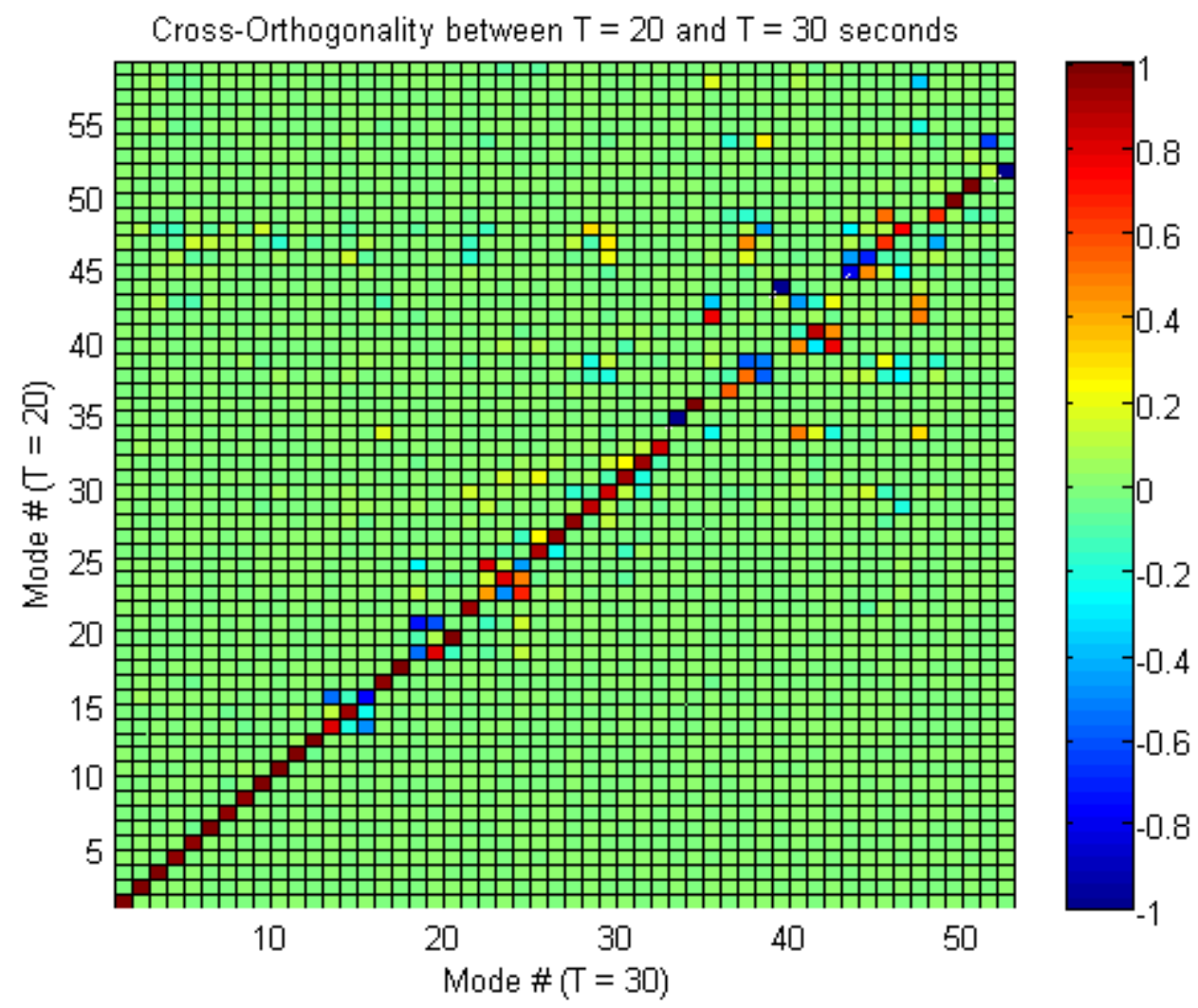

Figure 7 Cross-orthogonality matrix for $\mathrm{T}=20$ and $\mathrm{T}=30$ seconds.

Thirty dominant modes ( 24 of them elastic modes) for each time were down selected for design and analysis. Local and propellant modes, which have negligible effect on the OML, have been removed. Modes have been sorted so that the dominant response out of the 6 degrees of freedom of each mode was consistent from one time to the next. For the purposes of flight control system design, the first 13 flexible modes were used so that modal responses were modeled in bending, torsion, and axial modes. The higher frequency modes are far beyond the control system control bandwidth, and therefore are expected to have little effect on the analysis of stability and control characteristics.

\section{System Identification Maneuvers}

One key guiding philosophy that has been adhered to by the GN\&C team while developing the Ares I-X flight test plans has been to "Design for Data". Rather than simply flying a relevant trajectory and then attempting to reconstruct out of that trajectory clues to validate the design and analysis tools, the flight control system includes a mechanism to inject programmed test inputs (PTI) into the TVC actuator commands as well as into the command inputs to the pitch/yaw flight control system to provide inputs for system identification techniques to be used as part of the post-flight analysis. The PTI system is designed to provide key information on the structural dynamics responses, flight control system performance, and to enable aerodynamic force and moment model estimations. The maneuver inputs are pre-computed and are triggered as a function of time. The primary pitch and yaw maneuvers are designed to be input after the flight passes maximum dynamic pressure, and will conclude nearly 30 seconds before stage separation to allow the motions imparted to the rocket to damp before beginning the stage separation maneuver. Additionally there are several "blackout" periods of RoCS control. These blackout periods ensure that there will be opportunities throughout the flight to determine the combined aerodynamic and thrust-induced rolling moments acting on the flight test vehicle without interference from the RoCS. The times for the RoCS blackouts are input as parameters. These test methods have frequently been employed in aircraft flight test programs, but are uncommon and may be unprecedented for launch vehicle flight test. 


\section{A. Programmed Test Input Design}

The pitch / yaw PTI's consist of three 10-second optimized multi-sine sweeps to facilitate identification of control stability margins and aerodynamic response, and a brief pulse to identify the structural response. The first two sweeps are low amplitude sweeps (nominal peak 0.04 degree of TVC deflection) designed only for determination of stability margins. The first sweep is from 34-44 seconds to cover the transonic regime; this maneuver starts well after the gravity turn is established and the roll maneuver is complete. The second sweep runs from 48-58 seconds and covers the period of maximum dynamic pressure. The third sweep is a large amplitude (nominal peak 0.35 degree) sweep from 75-85 seconds and is intended to identify aerodynamic response as well as control stability margins. The structural pulse is a triangular pulse of 1.0 degree on yaw only, from 93.6 to 94.0 seconds.

The multi-sine TVC sweep inputs are designed to drive both the pitch and yaw channels simultaneously due to the limited maneuver time available. The waveforms consist of a sum of sines at discrete frequencies that are phaseoptimized to minimize the peak factor (and hence minimize deviations from the design trajectory due to PTI maneuvering). Additionally, the pitch and yaw waveforms are mutually orthogonal in both time- and frequency domains so that the effects of each can be identified without interference from the other despite being exercised simultaneously. This input design methodology is described in reference 3.

The sweeps cover the frequency range $0.2-2.5 \mathrm{~Hz}$. The pitch signal has content at $0.2,0.4, \ldots, 2.4 \mathrm{~Hz}$, while the yaw input is $0.3,0.5, \ldots, 2.5 \mathrm{~Hz}$. The power is biased toward the low frequencies, with a fourth-order roll-off for the large amplitude sweep and a cubic roll-off for the small amplitude sweeps. The power distributions for the sweeps are shown in Figure 8. The amplitude and power weightings for the low amplitude sweeps were designed to achieve reasonably good results in the stability margin calculations while keeping the input amplitude low due to the flight regimes (transonic and max Q) in which they will be used. The higher amplitude sweep was designed to obtain sufficient vehicle response (primarily angle of attack) to successfully identify the aerodynamic coefficients, while keeping the $\mathrm{Q}^{*} \alpha_{\mathrm{T}}$ product below $300 \mathrm{psf}$-degrees and TVC rates generally below $3 \mathrm{deg} / \mathrm{sec}$. This keeps these parameters from exceeding values normally reached during other portions of the flight. The resulting sweeps are shown in Figure 9 and Figure 10. The impact of the PTI's have also been evaluated using standard Monte Carlo techniques and results show that the PTI's are not a significant factor in the dispersed flight results. At this point, instrument noise models have not been available; the introduction of these noise models may require a re-design of these maneuvers to ensure that the system dynamic properties are still sufficiently observable in the presence of noise.
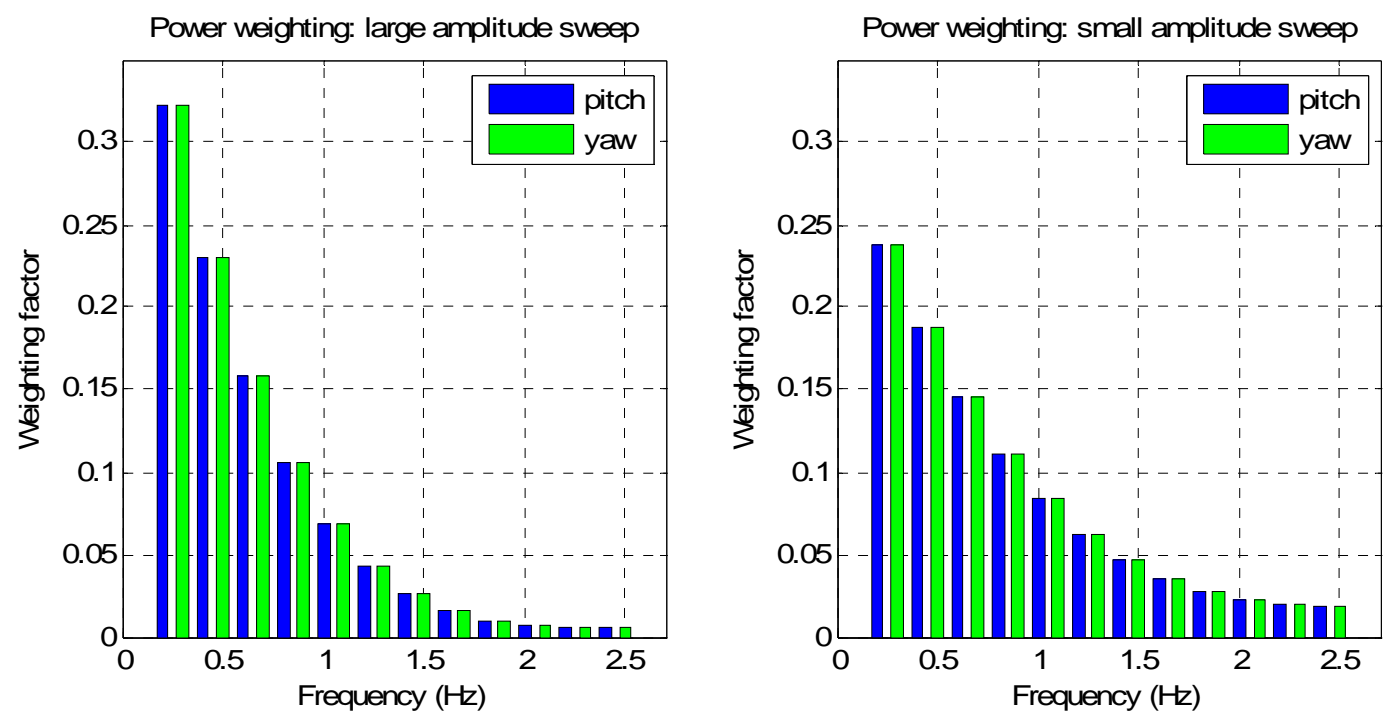

Figure 8 Power weighting for TVC sweeps. 


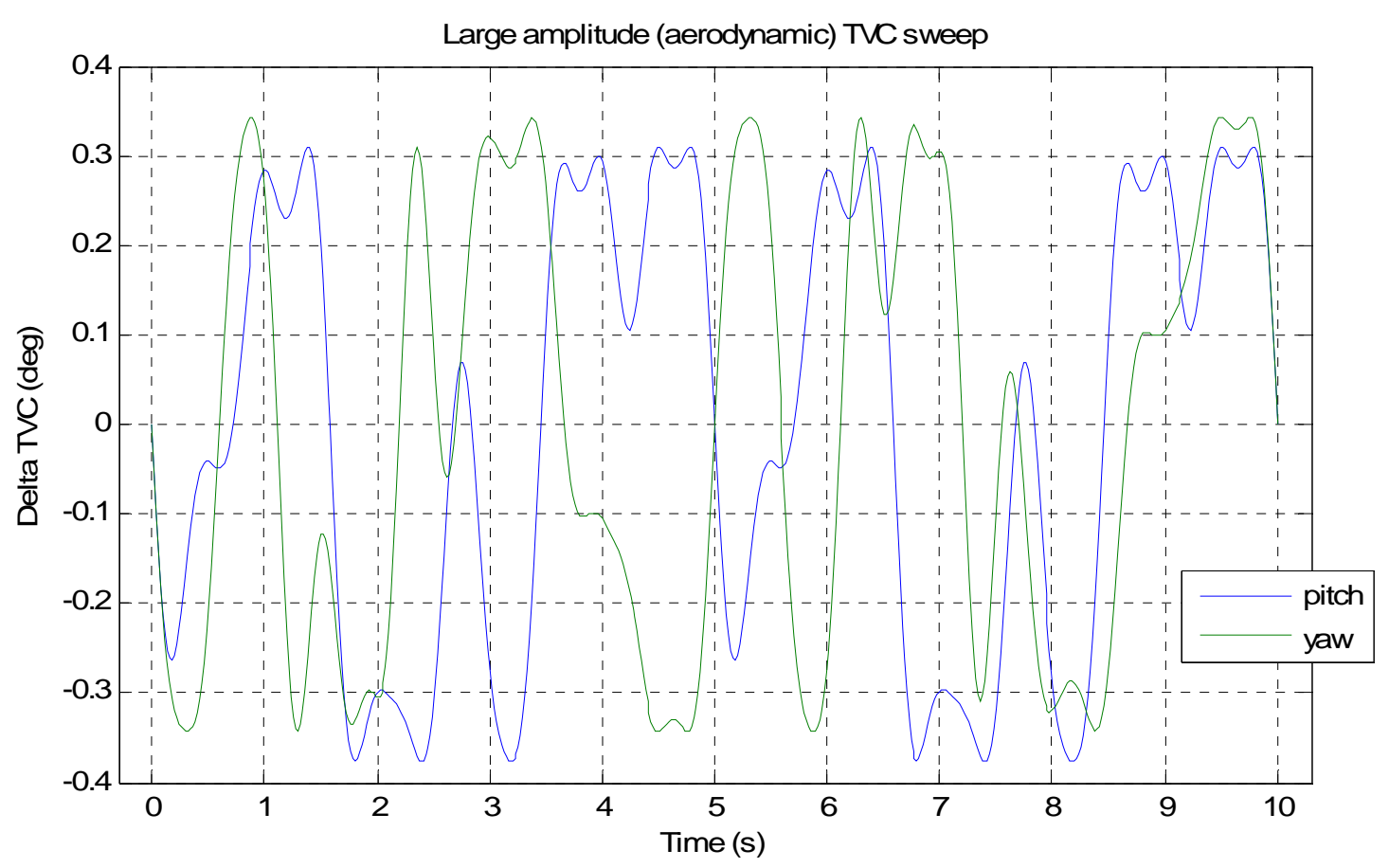

Figure 9 Time history of large amplitude sweep.

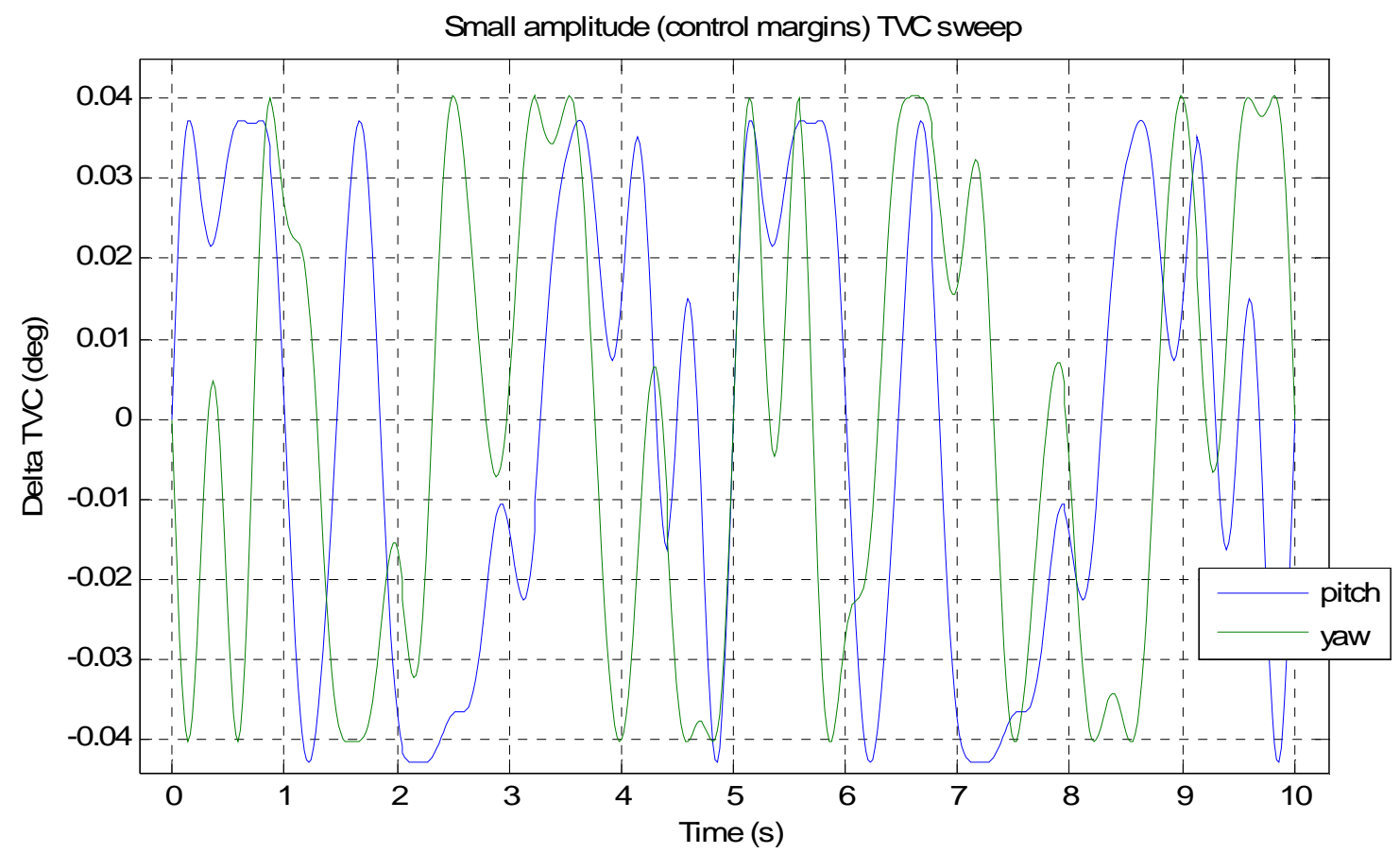

Figure 10 Time history of small amplitude sweep.

The structural pulse is applied only in the yaw channel, due to the similarity of the pitch and yaw structural response. The yaw channel was chosen because the guidance maneuvers, admittedly small, are primarily in the pitch axis at this point in the flight. The timing was chosen to be late enough so that aerodynamic effects and 
previous PTI maneuvers will not appreciably contaminate the response, but early enough so that the response will be largely damped out prior to the separation event.

The entire pitch / yaw PTI maneuver set, including all three sweeps and the pulse, is shown in Figure 11.

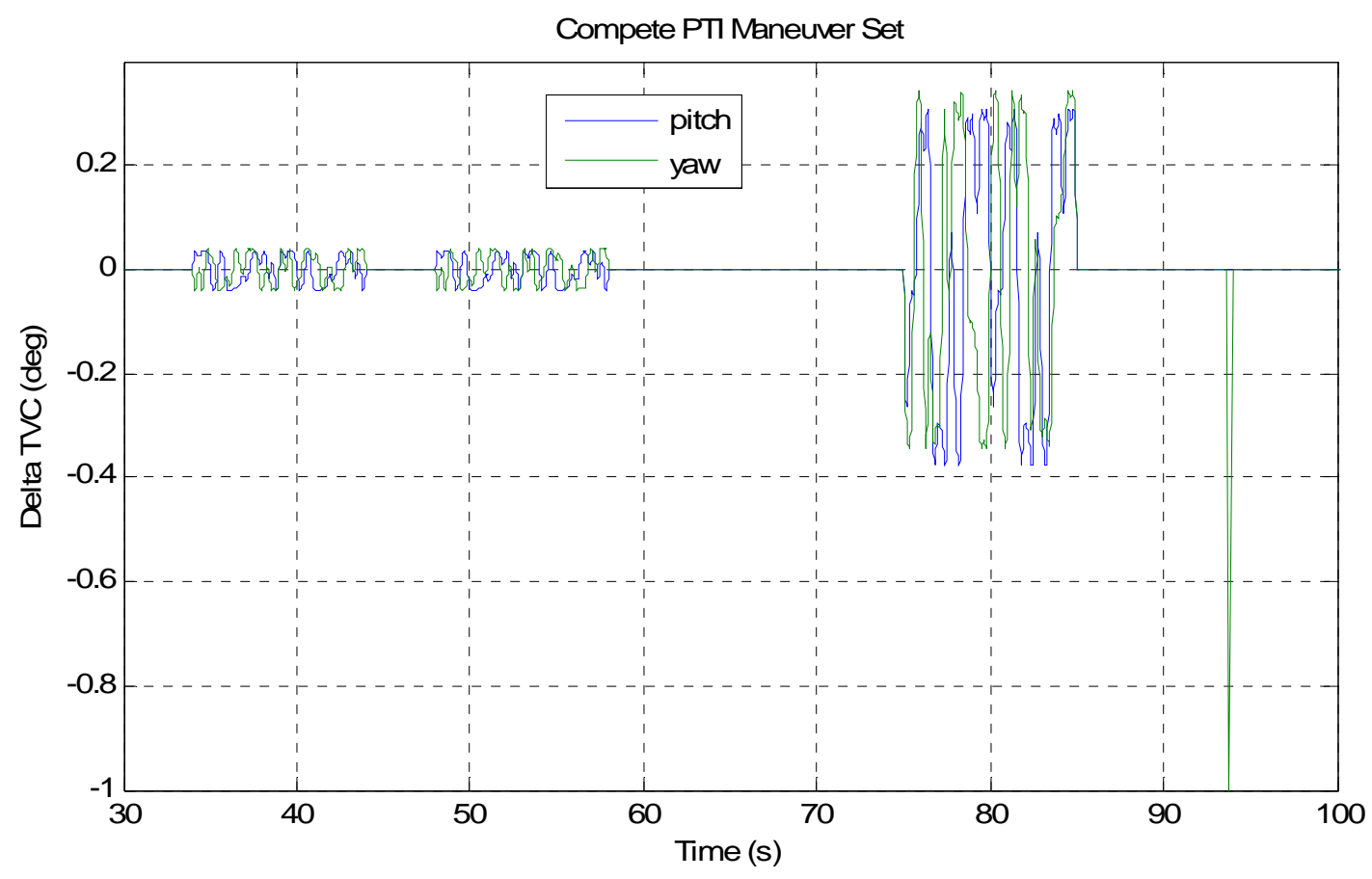

Figure 11 Complete PTI maneuver sequence.

\section{B. Impact to Flight Trajectory}

A pair of nominal case simulation runs, one with PTI and one without, were compared to assess the impact of the PTI on the flight. The assessment included the body axis rates, TVC deflections and rates, angles of attack, $\mathrm{Q}^{*} \alpha_{\mathrm{T}}$ products, mean body accelerations, structural responses, and trajectory deviations. Note that the PTI case had RoCS blackouts starting at 20 seconds, in addition to the pitch / yaw TVC inputs. Some results will be presented below.

Figure 12 shows the pitch and yaw body rates. The left-hand side shows the entire flight, to put the PTI maneuvers in context, and the right-hand side zooms in on the large-amplitude sweep and the pulse. The body rates imparted by the PTI maneuvers are significantly smaller than those resulting from the trajectory maneuvers earlier in the flight. Also, the rates coalesce back to the non-perturbed flight values at the completion of the maneuver. 

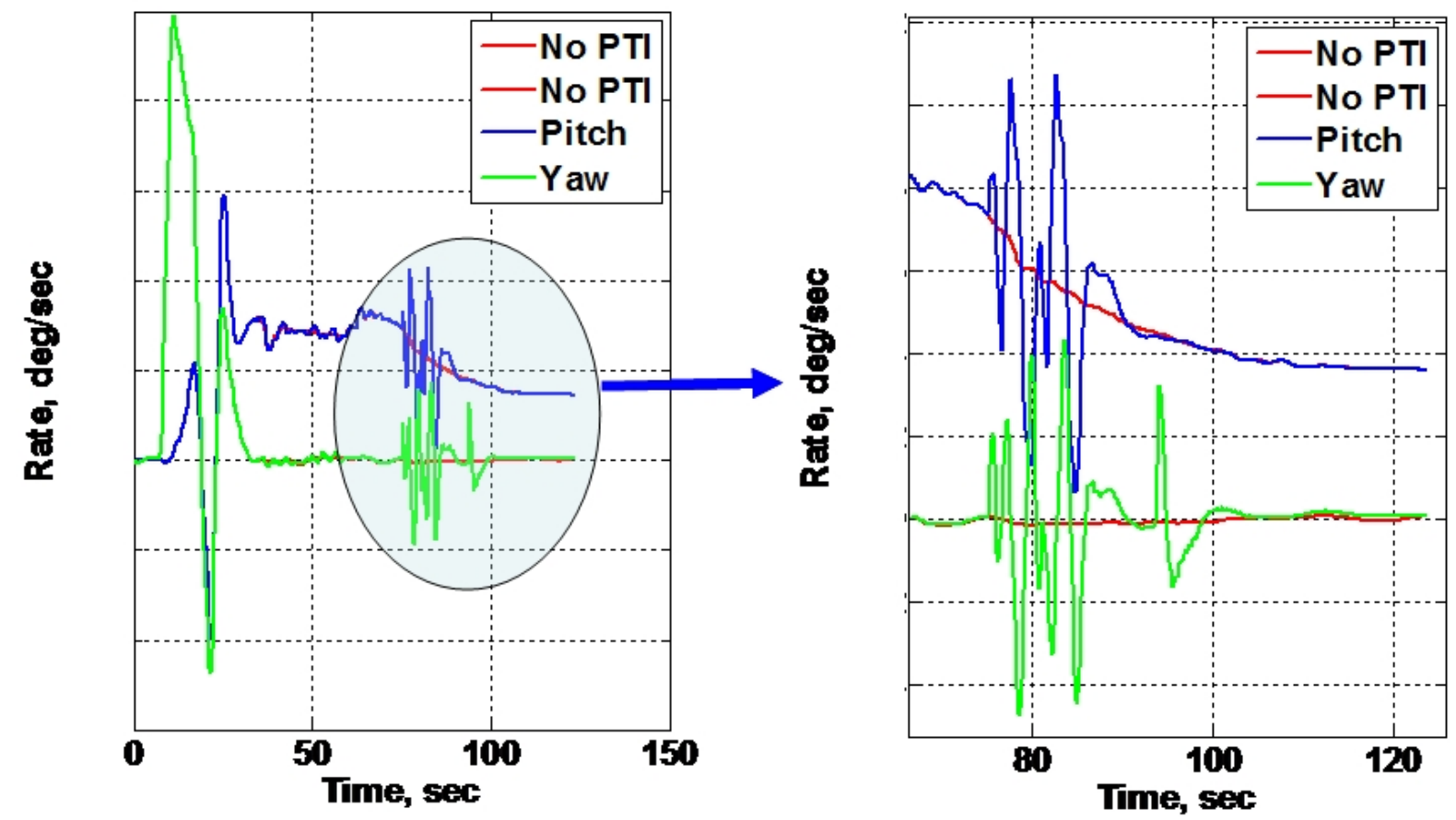

Figure 12 Impact of PTI's on body rates.

Figure 13 shows that the impact of the system identification maneuvers on the aerodynamic incidence angles is negligible except during the large amplitude inputs where the objective is to excite some angle of attack and sideslip response for aerodynamic model identification. The sideslip excursion around 93 seconds is due to the yaw pulse added for structural model excitation. Figure 14 shows a load indicator $\left(\mathrm{Q}^{*} \alpha_{\mathrm{T}}\right)$ and it is seen that the inclusion of the PTI's does increase the load somewhat where they are used, however the overall loads on the vehicle remain much lower than the loads already seen earlier in the flight due to normal maneuvering.
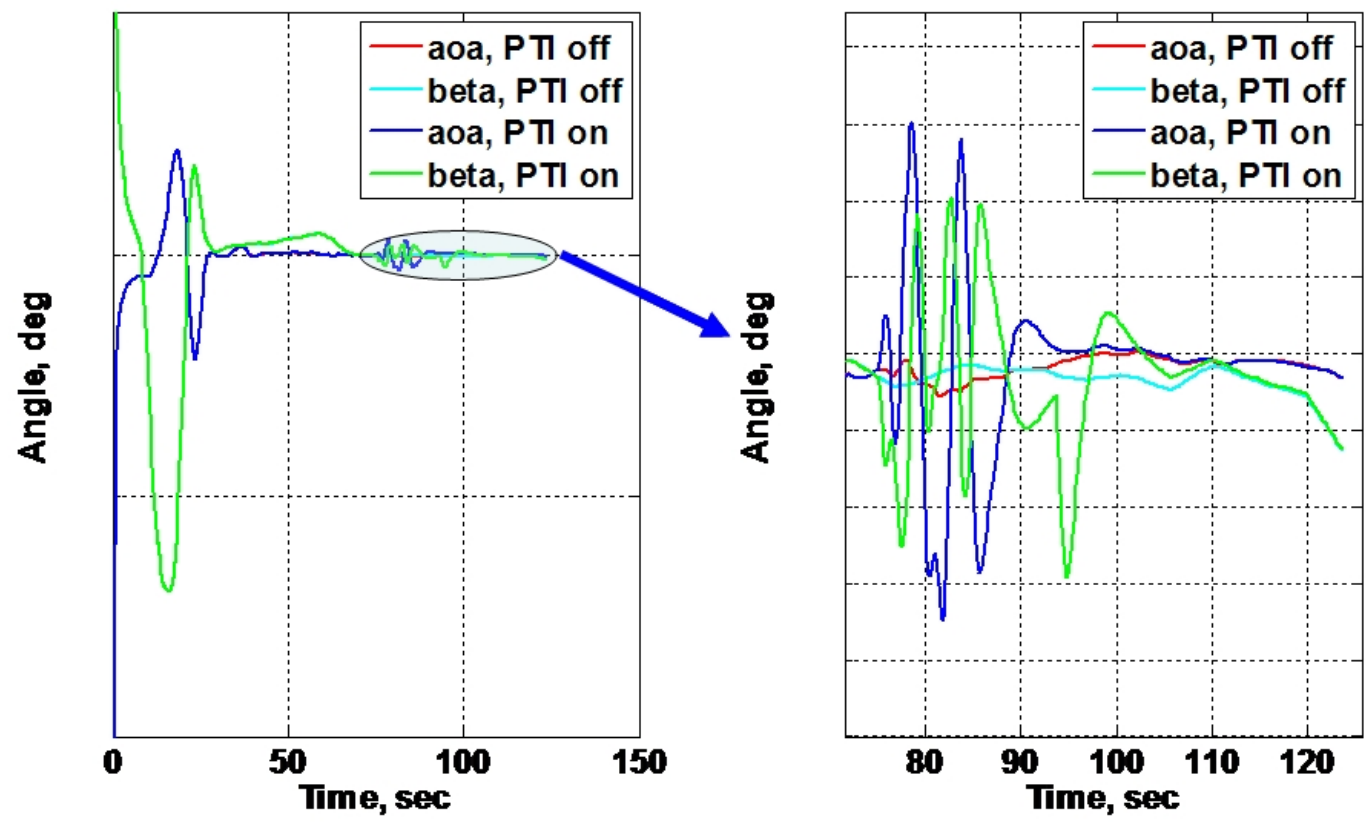

Figure 13 Incidence angles due to PTI's. 


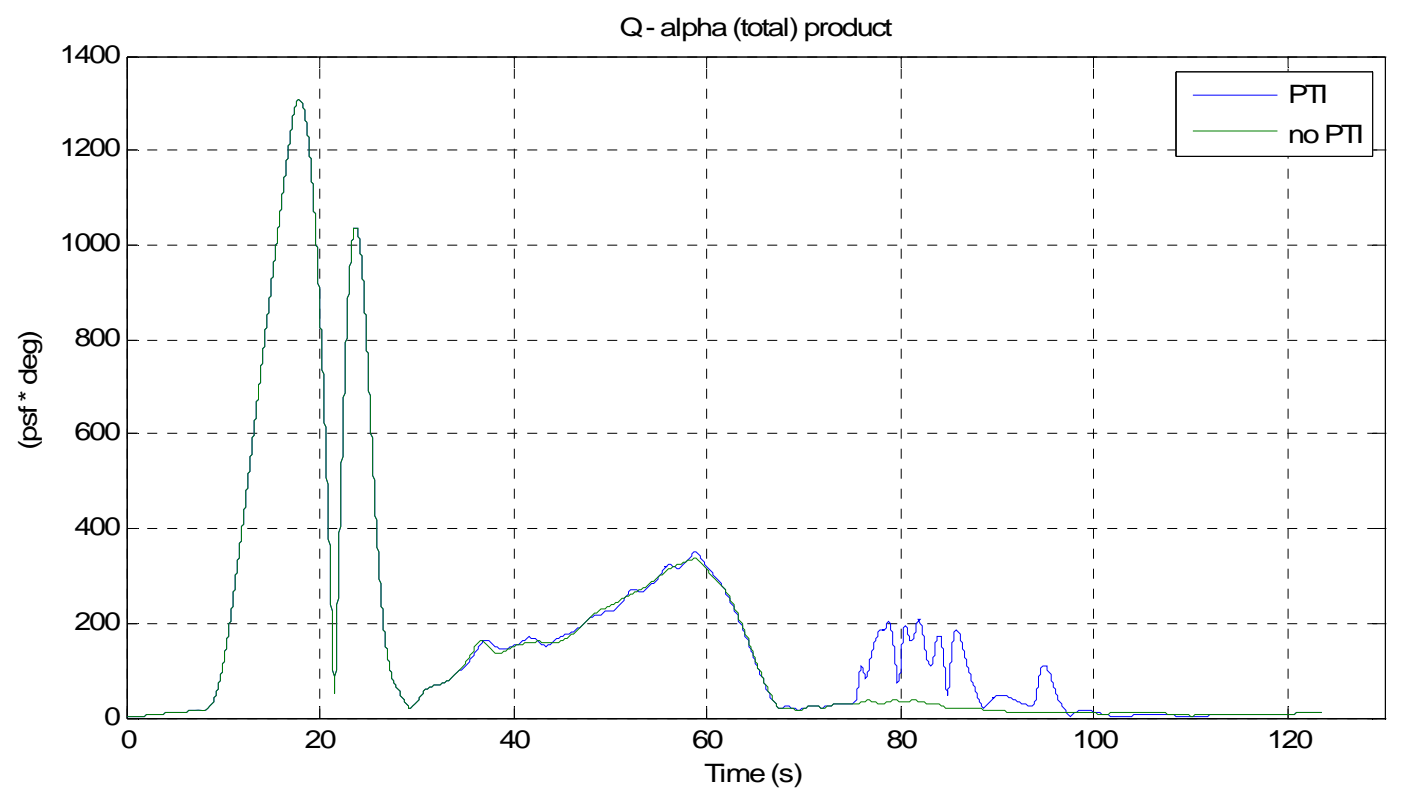

Figure 14 Dynamic pressure - total angle of attack product with and without PTI.

\section{Analysis Approach}

The post-flight analysis of the system identification maneuvers starts with data from several sources. A-priori data will include geometry, mass properties, RSRM and RoCS thrust, and base drag. Post-flight adjustments should be made, to the RSRM thrust in particular, to improve the match to the as-flown system. The telemetry stream, from both operational flight instrumentation (OFI) and development flight instrumentation (DFI), includes TVC commands and actuator and RoCS activity. The TVC positions should be adjusted to account for local structural deflections if adequate information or high fidelity models are available. The Best Estimated Trajectory (BET) data set will be utilized as the source for all inertial and air-relative data.

The control stability margins can be estimated with OFI telemetry alone. Once the BET is available, the total forces and moments will be reconstructed. The thrust forces and moments (including RSRM and RoCS, as well as TVC gimbal inertial reactions) will be modeled and subtracted to yield the aerodynamic forces and moments, which will be reduced to non-dimensional coefficients. The aerodynamic model structure will be determined and the model parameters estimated using several time- and frequency-domain techniques. The structural modal frequencies will be determined utilizing a PSD of the inertial data from the telemetry, and mode shape correlation with finite element models will be conducted using acceleration measurements available from the installed flight instrumentation.

The aerodynamic system identification, in particular, will likely be more difficult for this flight than is typically the case for aircraft flight tests due to three factors. First, the perturbation range of the angles of attack and sideslip is smaller, 0.6 degrees at most, versus aircraft tests which seek to produce excursions of several degrees. Second, the forces and moments on the Ares I-X are thrust-dominated, whereas those on aircraft are generally dominated by aerodynamics. Since the thrust forces and moments are modeled and subtracted, any modeling errors will appear as (incorrect) aerodynamic effects, which will be proportionately larger as a result. Finally, due to the rapid acceleration inherent to the flight, the time available for data collection is limited and the aerodynamic characteristics will vary somewhat even over the short interval due to the rapid change in Mach number. 
An example of control stability margins estimation and comparison with linear analysis results is shown in Figure 15. These data are obtained by comparing the command signals (from the FCS plus the PTI) going into the TVC mixer (command) versus those from the FCS alone (response) in frequency domain.

The time domain command and response data are quantized to 16 bits (similar to the flight telemetry) and then converted to frequency domain using a Chirp z-Transform with cubic interpolation of the time domain inputs. This method is documented in reference 2. A 12-second raised-cosine window is analyzed centered about each 10second PTI sweep. Simple spectral techniques are used that involve no averaging or smoothing. It is anticipated that another method, that of approximating the response with a low-order equivalent system, will be used in addition to the spectral method. These methods have been applied successfully to recent aircraft flight test programs, such as the X-29, X-31, X-38, and X-43A (References 4-7).

GinBode

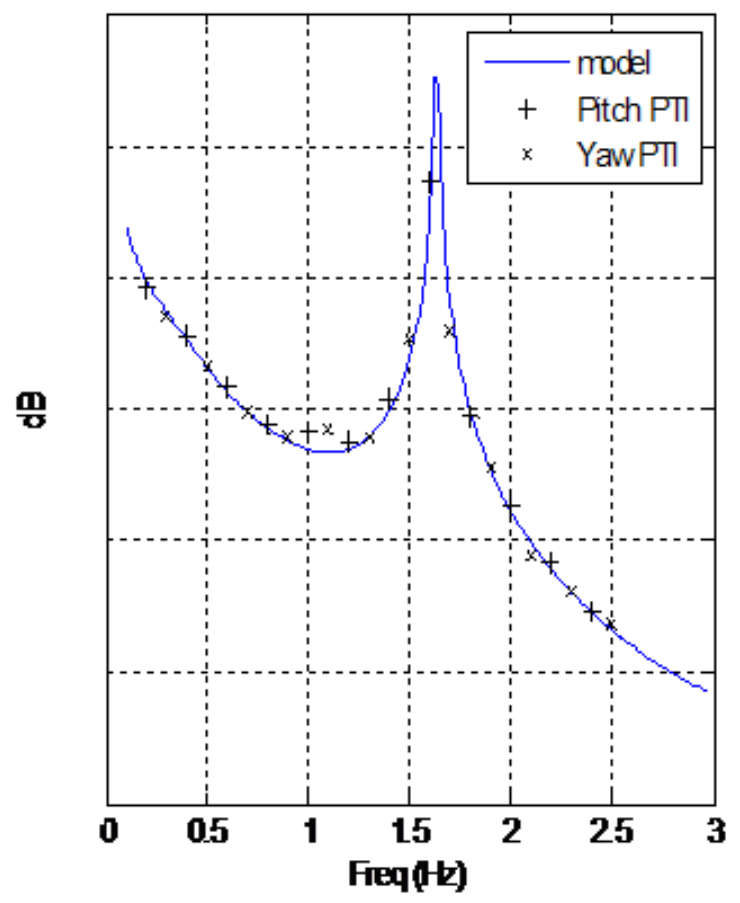

Frase Bote

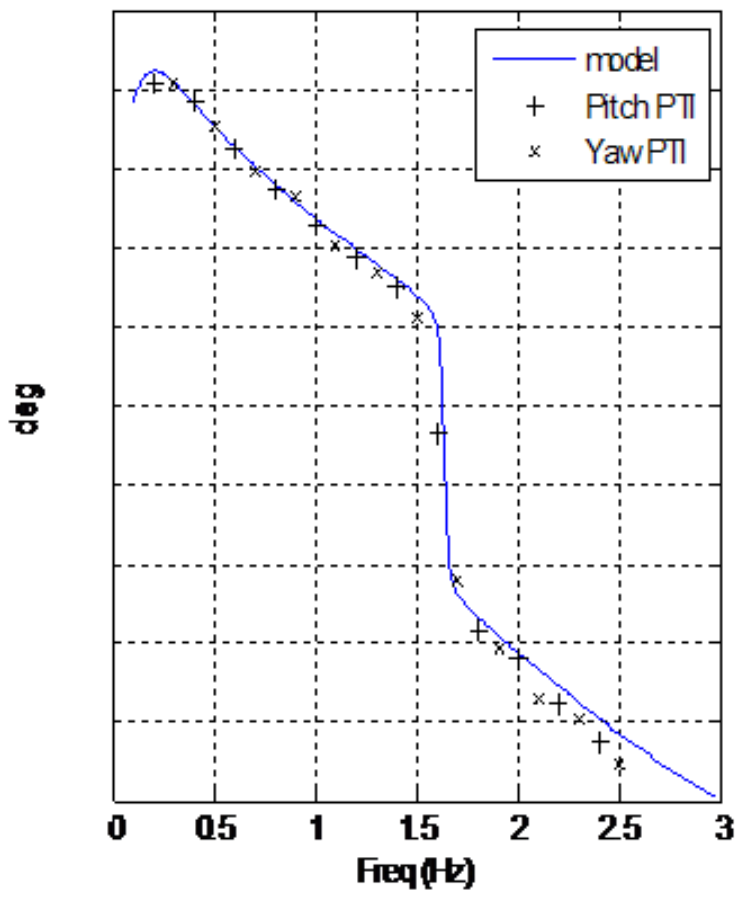

Figure 15 Bode plots of control response for the max Q condition.

An example of the aerodynamic model identification from the third PTI pitch/yaw input is shown below for pitch stability. The aerodynamic model used in the flight simulation code has $\mathrm{C}_{\mathrm{m}}$ as functions of total angle of attack $\left(\alpha_{\mathrm{T}}\right)$, Mach number, and aerodynamic roll angle and does not include an estimate for rate damping. The model structure used in the parameter estimation has $\mathrm{C}_{\mathrm{m}}=\mathrm{C}_{\mathrm{m} \alpha} \alpha$ i.e., a local linearization. Due to the symmetry of the model, $\mathrm{C}_{\mathrm{n} \beta}=$ - $\mathrm{C}_{\mathrm{m} \alpha}$, so both pitch and yaw inputs can be combined to obtain more data from flight maneuvers. The parameter estimation was performed using the equation error method and a least-squares estimator in both time and frequency domains. In post-flight analysis, we will also consider the use of the output error method with a maximumlikelihood estimator in the frequency domain. White noise was added to the simulated TVC telemetry. A $0.5 \mathrm{~Hz}$ low-pass filter was applied to the outputs and regressors.

Figure 16 shows the result of the identified pitching-moment derivative and compares the result with the simulation database values. The PTI maneuver took place over a wide Mach range (2.6 to 3.2); the "truth" (simulation database) values for $\mathrm{C}_{\mathrm{m} \alpha}$ are shown along with the estimates and estimated error bounds, and the estimated result falls in line nicely with the simulation model values. 
Although the parameter estimation process included attempts to identify rate damping terms as well, it found none (since the simulation model did not include damping terms, and they will likely be small in flight), and they were not included in the final identified model. When performing the parameter estimation on the flight data, we will attempt to identify damping. This will likely be unsuccessful unless the aerodynamic damping is significant.

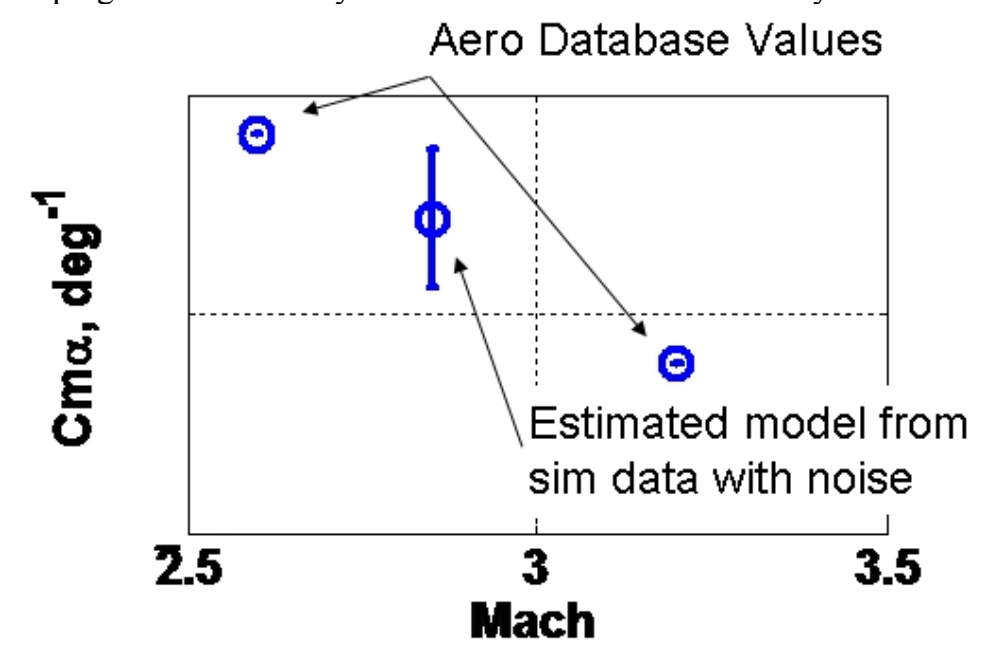

Figure 16 Aerodynamic math model identification example.

\section{Status}

The Ares I-X flight test project is well underway. Hardware is currently in fabrication with the upper stage simulator being built at the NASA Glenn Research Center, the CM/LAS simulator being built at the NASA Langley Research Center, and the first stage (booster) being modified by ATK and other contractor companies. Avionics hardware is based on the Atlas V equipment and is being integrated by United Launch Alliance / Lockheed. The flight control laws have been developed and analyzed. Analysis was sufficiently completed in all areas to have completed the integrated vehicle critical design review in July 2008. The development project is continuing to improve physical models of the vehicle - including new wind tunnel test data, aeroelastic analyses and structural model updates, and as new information is obtained, the flight control system design and analysis cycle is repeated to verify that the algorithms still provide the desired performance and stability. The flight control system gains and filter coefficients values are parameterized so that changes required are easily updated and tested in the flight computer. Hardware-in-the-loop testing with the flight control computer is currently underway.

\section{Final Remarks}

A new manned space exploration architecture is being developed to provide access to the International Space Station, Moon, and beyond. The component of the new architecture that provides the manned vehicle access to orbit is the Ares I and Orion. The Ares I is based on Space Shuttle heritage components, however most heritage components require modifications for use in this new vehicle. The overall design of the launch vehicle is a long slender rocket with the Orion capsule on the top. The large vehicle length, use of a solid-fuel booster, aerodynamic instabilities, and vehicle flexibility all pose potential challenges in control and operations of the vehicle. The Ares I$\mathrm{X}$ flight test will provide valuable information for design guidance and validation of analysis tools used for Ares I. A unique aspect to this flight test is that it is being designed for the collection of flight dynamics data. This involves including small pre-programmed test inputs as part of the control system design. By including these maneuvers, detailed modeling data should be able to be obtained to validate control system stability relative to the design results, and to anchor some aerodynamic and structural dynamics modeling.

\section{References}

${ }^{1}$ Program to Optimize Simulated Trajectories: Volume II, Utilization Manual, prepared by: R.W. Powell, S.A. Striepe, P.N. Desai, P.V. Tartabini, E.M. Queen; NASA Langley Research Center, and by: G.L. Brauer, D.E. Cornick, D.W. Olson, F.M. Petersen, R. Stevenson, M.C. Engel, S.M. Marsh; Lockheed Martin Corporation, Version 1.1.1.G, May 2000. 
${ }^{2}$ Morelli, Eugene, A.: High Accuracy Evaluation of the Finite Fourier Transform Using Sampled Data. NASA TM 110340 , June 1997.

${ }^{3}$ Morelli, Eugene, A.: Multiple Input Design for Real-Time Parameter Estimation in the Frequency Domain. IFAC Conference on System Identification, Rotterdam, August 2003.

${ }^{4}$ Bosworth, John, T.: Flight-Determined Longitudinal Stability Characteristics of the X-29A Airplane using Frequency Response Techniques. NASA TM 4122, 1989.

${ }^{5}$ Bosworth, John, T. and Stachowiak, Susan, J.: Real-Time Stability Margin Measurements for X-38 Robustness Analysis. NASA TP 2005-212856, February 2005.

${ }^{6}$ Bosworth, John, T. and Burken, John J.: Tailored Excitation for Multi-Variable Stability-Margin Measurement Applide to the X-31A Nonlinear Simulation. NASA TM 113085, 1997.

${ }^{7}$ Baumann, Ethan: Tailored Exitation for Frequency Response Measurement Applied to the X-43A Flight Vehicle. AIAA 2006-638, 44 ${ }^{\text {th }}$ Aerospace Sciences Meeting and Exhibit, Reno, NV, January 2006. 